\title{
Structure of and Signalling Through Chimeric Antigen Receptor
}

\author{
Christian Chabannon (i) and Chiara Bonini
}

Chimeric antigen receptor (CAR) is a synthetic transmembrane protein expressed at the surface of immune effector cells (IECs) that are reprogrammed either in vitro or in vivo (June et al. 2018; June and Sadelain 2018). Techniques for genetic engineering of autologous or allogeneic IECs are described in the next chapter. The synthetic CAR incorporates several functional domains. The extracellular domain is composed of a single chain variable fragment $(\mathrm{ScFV})$ of immunoglobulin and recognizes the "tumour" antigen. The clinical relevance of the selected tumour antigen-with a view to minimize "on-target/off-tumour" side effects-is discussed in the third chapter of this section. Bispecific and trispecific CARs are currently being evaluated in preclinical and early clinical trials (Bielamowicz et al. 2018; Shah et al. 2020). The use of an immunoglobulin domain as the ligand of the target antigen means that recognition is not restricted to HLA antigens and that CAR-T cells are universally applicable as opposed to $\mathrm{T}$ cell receptor (TCR) transgenic T cells that recognize antigenic peptides presented in the context of a defined major histocompatibility complex (MHC), limiting clinical applications to subsets of patients with defined HLA typing. The intracellular domain is composed of the intracellular domain of the zeta chain of the CD3 component of the TCR, which will trigger signalling when the CAR engages the targeted ligand. The transmembrane region links the two extracellular and intracellular domains through the cell membrane and plays an important role in determining the conformation and flexibility of the CAR and its ability to efficiently bind the targeted

\footnotetext{
C. Chabannon $(\bowtie)$

Institut Paoli-Calmettes, Centre de Lutte Contre le Cancer, Centre d'Investigations Cliniques en Biothérapie, Université d'Aix-Marseille, Inserm CBT-1409, Marseille, France

e-mail: CHABANNONC@ipc.unicancer.fr

C. Bonini

Experimental Hematology Unit, Division of Immunology, Transplantation and Infectious Diseases, Vita-Salute San Raffaele University, IRCCS Ospedale San Raffaele Scientific Institute, Milan, Italy

e-mail: bonini.chiara@hsr.it
} 
antigen/epitope. Association of only these three functional domains characterized first generation CARs, as described in the original publications (Kuwana et al. 1987; Eshhar et al. 1993). However, full activation of $\mathrm{T}$ cells requires the addition of one (second generation CARs) or two (third generation CARs) domains from costimulatory molecules, such as CD28, 4-1BB/CD137, or OX40/CD134, that provide the T cell costimulatory signal. Currently approved CAR-T cells are second generation CAR-T cells; as an illustration, the CAR in tisagenlecleucel contains a 4-1BB domain, while the CAR in axicabtagene ciloleucel contains a CD28 domain. The nature of the costimulatory domain influences the ability of CAR-T cells to expand or persist (limit T cell exhaustion) in vivo after infusion into the patient, although it is unclear how this translates clinically and affects disease control, occurrence of adverse events, and overall survival due to the lack of head-to-head comparison between approved products. Finally, fourth generation CAR-T cells have been developed for preclinical projects. These cells, named armoured CAR cells or $\mathrm{T}$ cells redirected for universal cytokine-mediated killing (TRUCKS), encode not only a CAR (usually with one costimulatory domain, such as in second generation CARs) but also a cytokine, interleukin, pro-inflammatory ligand, or chemokine that will counteract the immune suppressive microenvironment that prevails in most solid tumours (Eshhar et al. 1993; Chmielewski and Abken 2015).

When the CAR engages its ligand, signalling involves several components of the naturally occurring TCR. These include molecules such as lymphocyte-specific protein tyrosine kinase (LCK). Some components of the signalling cascade are actionable with existing drugs, which offers opportunities for pharmacologic modulation of CAR activity in vivo, such as described with tyrosine kinase inhibitors (Mestermann et al. 2019; Weber et al. 2019); this represents an appealing alternative to the inclusion of a suicide gene in the CAR construct (Casucci et al. 2013; Gargett and Brown 2014; Sakemura et al. 2016). Synthetic biology applied to the CAR-T cell field led to engineering of combinatorial antigen recognition constructs. The "OR" gate strategy (i.e., CD19 and CD22) allows CAR-T cell activation upon recognition of at least 1 of the 2 targeted antigens, thus reducing the risk of cancer immune evasion. The "OR" and "NOT" gate strategies are designed to improve the safety profile of CAR-T cells, since tumour cells and healthy cells can be discriminated by CAR-T cells based on the expression pattern of 2 antigens (Weber et al. 2020).

\section{Key Points}

- A chimeric antigen receptor is a synthetic transmembrane molecule encoded by a DNA sequence that combines domains from immunoglobulins, one chain of the T cell receptor, and typically domains from costimulatory molecules involved in $\mathrm{T}$ cell activation.

- Currently approved and commercially available CAR-T cells are second generation CAR-T cells that contain a single costimulatory domain.

- The machinery for cell signalling contains actionable elements, thus offering opportunities for in vivo modulation of CAR-T cell activities and mitigation of adverse events. 


\section{References}

Bielamowicz K, Fousek K, Byrd TT, Samaha H, Mukherjee M, Aware N, et al. Trivalent CAR-T cells overcome interpatient antigenic variability in glioblastoma. Neuro-Oncology. 2018;20(4):506-18.

Casucci M, Nicolis di Robilant B, Falcone L, Camisa B, Norelli M, Genovese P, et al. CD44v6targeted $\mathrm{T}$ cells mediate potent antitumor effects against acute myeloid leukemia and multiple myeloma. Blood. 2013;122(20):3461-72.

Chmielewski M, Abken H. TRUCKs: the fourth generation of CARs. Expert Opin Biol Ther. 2015;15(8):1145-54.

Eshhar Z, Waks T, Gross G, Schindler DG. Specific activation and targeting of cytotoxic lymphocytes through chimeric single chains consisting of antibody-binding domains and the gamma or zeta subunits of the immunoglobulin and T-cell receptors. Proc Natl Acad Sci U S A. 1993;90(2):720-4.

Gargett T, Brown MP. The inducible caspase-9 suicide gene system as a "safety switch" to limit ontarget, off-tumor toxicities of chimeric antigen receptor T cells. Front Pharmacol. 2014;5:235.

June CH, Sadelain M. Chimeric antigen receptor therapy. N Engl J Med. 2018;379(1):64-73.

June CH, O'Connor RS, Kawalekar OU, Ghassemi S, Milone MC. CAR-T cell immunotherapy for human cancer. Science. 2018;359(6382):1361-5.

Kuwana Y, Asakura Y, Utsunomiya N, Nakanishi M, Arata Y, Itoh S, et al. Expression of chimeric receptor composed of immunoglobulin-derived $\mathrm{V}$ regions and T-cell receptor-derived $\mathrm{C}$ regions. Biochem Biophys Res Commun. 1987;149(3):960-8.

Mestermann K, Giavridis T, Weber J, Rydzek J, Frenz S, Nerreter T, et al. The tyrosine kinase inhibitor dasatinib acts as a pharmacologic on/off switch for CAR-T cells. Sci Transl Med. 2019;11(499):eaau5907.

Sakemura R, Terakura S, Watanabe K, Julamanee J, Takagi E, Miyao K, et al. A Tet-On inducible system for controlling CD19-chimeric antigen receptor expression upon drug administration. Cancer Immunol Res. 2016;4(8):658-68.

Shah NN, Johnson BD, Schneider D, Zhu F, Szabo A, Keever-Taylor CA, et al. Bispecific antiCD20, anti-CD19 CAR-T cells for relapsed B cell malignancies: a phase 1 dose escalation and expansion trial. Nat Med. 2020;26(10):1569-75.

Weber EW, Lynn RC, Sotillo E, Lattin J, Xu P, Mackall CL. Pharmacologic control of CAR-T cell function using dasatinib. Blood Adv. 2019;3(5):711-7.

Weber EW, Maus MV, Mackall CL. The emerging landscape of immune cell therapies. Cell. 2020;181(1):46-62.

Open Access This chapter is licensed under the terms of the Creative Commons Attribution 4.0 International License (http://creativecommons.org/licenses/by/4.0/), which permits use, sharing, adaptation, distribution and reproduction in any medium or format, as long as you give appropriate credit to the original author(s) and the source, provide a link to the Creative Commons license and indicate if changes were made.

The images or other third party material in this chapter are included in the chapter's Creative Commons license, unless indicated otherwise in a credit line to the material. If material is not included in the chapter's Creative Commons license and your intended use is not permitted by statutory regulation or exceeds the permitted use, you will need to obtain permission directly from the copyright holder.

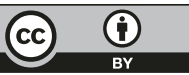

